\title{
10. Give or Take: A comparative analysis of demand sharing among the Menraq and Semai of Malaysia
}

\author{
Alberto Gomes \\ La Trobe University
}

Nicolas Peterson's concept of 'demand sharing', in which goods and services are exchanged 'by taking rather than giving' (Peterson 1993: 861) and in which the driving motivation is something other than unsolicited generosity, raises several theoretical and comparative questions pertinent to the anthropology of gift giving (cf. Altman, Kwok, Martin and Saethre, this volume). In this chapter, I discuss the practice of 'demand sharing' in two ethno-linguistically different Orang Asli (Malaysian aboriginal) tribal communities. Through a comparative analysis of exchange relations that I have observed among the Menraq of Kampung Rual (hereafter shortened to Rual Menraq) and in a Semai village, Kampung Lengap (hereafter Lengap Semai), ${ }^{1}$ I explore the social and economic conditions underlying the practice of demand sharing. In particular, I assess Peterson's contention that the practice of demand sharing among Australian Aborigines needs to be apprehended in the context of changing economic conditions. The Rual Menraq were once nomadic foragers while the Lengap Semai were subsistence-focused swidden horticulturalists who have become simple commodity producers, mainly on their own accord. In 1972, the Malaysian Government encouraged the Rual Menraq to leave their nomadic existence for a settled lifestyle in a Malay-styled village. The explicit rationale for this resettlement was to facilitate the implementation of various development projects designed to transform the economy of the people from foraging into simple commodity production. They now depend on their governmentsponsored plantations of rubber trees, oil palm and tropical fruit for the bulk of their income and no longer have ready or reliable access to forest products - a consequence of deforestation of their home territories by commercial logging and land clearing by recent Malay settlers in the area. The Rual population has doubled from about 200 in 1975 to slightly more than 400 in 2006. In 1994, most of the Rual Menraq were converted to Islam as part of the Malaysian Government's social development program for the Orang Asli. A pertinent

\footnotetext{
1 The ethnographic data presented here are drawn from Gomes $(2004,2007)$. The Menraq are identified by the Malaysian authorities and in several studies as 'Negritos'. They are also known as Semang in older literature. I have decided to adopt the more appropriate autonym 'Menraq'.
} 
question is whether such a radical change in economic, social and religious life has had an impact on Menraqs' traditional forms of social and moral conduct, such as their sharing ethic and practice. This is a question I will return to later.

The Semai, constituting the largest Orang Asli population at approximately 45000 people, have survived for a very long time as subsistence-oriented, forest-dependent farmers. They were initially pushed into the hinterland by Malay settlers and subsequently, and more aggressively, by state-sponsored plantations and mining industries. They were victims of Malay slavers during the eighteenth and nineteenth centuries and this shaped their fear of interaction with the outside world. Infrastructural development such as roads and railway, expansion of agricultural plantations, and extractive industries such as timber logging and tin mining exposed the Semai to further displacement-sometimes disguised as government-directed resettlement programs. Their subsistenceoriented pursuits were considered traditional and backward, thus requiring the benefits of modernisation. They were, and still are, regarded as people with a weak connection to their land. All in all, Semai have been, and continue to be, viewed as backward tribal people who will step into the modern world - or, in the official parlance, 'into the mainstream of society' - only with the assistance of the Government and development agencies. Lengap village, however, where I carried out anthropological field research in the early 1980s, has over the years developed links with the market economy despite minimal government assistance. Numbering about 200 people, Lengap Semai have engaged in the trading of forest products for centuries, but in more recent times have become increasingly entrenched in a commoditised economy in which they trade commodities such as rattan, petai and durian in exchange for most of their food and other needs.

\section{Opportunistic Foragers and the Insider- Outsider Dichotomy}

In his introduction to the republication of Schebesta's Among the Forest Dwarfs, Geoffrey Benjamin observes of the Menraq:

They are neither 'hunters' nor 'nomads' at base, even though they frequently do engage in these activities. Rather, they turn their attention to whatever is available for the moment, and as soon as one source of provender is exhausted they turn to something else. At various times any one group of Negritos may jointly or individually trade, barter, undertake casual paid employment, beg, fish, gather, or live off the gifts of visiting anthropologists. (Benjamin 1973: viii) 
Benjamin appropriately labelled the Menraq 'opportunistic foragers'. What is implied here is that Menraq would 'take' any opportunity to obtain a share of any property, including that supplied by anthropologists. When I first visited Rual in 1975, I encountered incessant demands from the people for food and other material goods. Gaining familiarity with the behaviour of people at Rual, I have resorted to a range of strategies to ward off such demands, similar to Nicolas Peterson's ploy of keeping 'large-denomination bills in one pocket and smaller change in another' in his response to demands for money from him by Aboriginal people in Alice Springs (Peterson 1993: 864). After I was considered as 'one of us' or as 'family' by the Menraq, their demands for me to share have reduced drastically. ${ }^{2}$ In fact, these days people hint, rather than demand, for a share. While Peterson (1993: 862) recognises that demand sharing 'did not always take spoken form', he does not make a qualitative distinction between verbal and non-verbal demands - a distinction that I would argue is analytically pertinent and valid.

The change in the behaviour and attitude of the Menraq towards an outsider is a reflection of the acceptance of the outsider into their 'known world'. In his essay on headhunting in South-East Asia, Robert McKinley (1976: 105) described what he considers a common South-East Asian tribal cosmology. He has referred to the cosmological centre as the 'known world', which he delineates as 'the earth and its inhabitants who are one's own fellow villagers'. Among most of the Orang Asli, members of their 'known world' are referred to by vernacular terms for 'human' or 'people' such as Senoi, Menraq or Meniq. People who are external to this world are referred to as gob by most, if not all, Orang Asli communities. Gob, usually translated by anthropologists as 'stranger' or 'foreign', is a term that Orang Asli use almost exclusively to refer to Malays. They might, however, refer to Chinese Malaysians and Indian Malaysians as Gob Cina or Gob India respectively. Among the Iban of Sarawak, 'living strangers' are referred to as orang bukai, which McKinley (1976: 108) translates as 'people negated' or 'people who are not people'. What makes gob, or orang bukai in the case of the Iban, 'strangers' is the fact that they do not live in the 'known world' of Orang Asli 'humanity' or 'people-hood' and, more importantly, they are perceived not to share or observe Orang Asli 'internal culture'. Sellato (1994: 210-11) uses the term 'internal culture' to refer to the habitus (after Bourdieu), which he defines as 'a system of lasting and transferable patterns of thought and behavior that regulates social and economic activities and is passed on from generation to generation through all the vicissitudes of history and changes in the "external culture"". The Orang Asli, like many other tribal communities in South-East Asia, observe what Sellato (1994: 210) in the context of his study on

2 When the Islamic religious teacher residing at Rual asked the people about the purpose of my visit during one of my field visits in the late 1990s, I was told that several Rual Menraq responded that I was related to them. Evidently an elder retorted, 'Can't my son visit me? I've known him since he was a young boy.' 
the Punan, a hunting-gathering people of Borneo, calls 'double life'. The people adhere to a set of rules and norms in their intra-community interactions but present a different face to outsiders. In the case of Menraq, the salient features of their internal culture include an egalitarian outlook, a high value placed on personal autonomy, gregariousness towards each other with the exception of encounters with people implicated in cross-sex avoidances, a non-aggressive or non-aggrandising behaviour towards fellow community members and an adherence to a sharing ethic. In the case of the sharing ethic, it is governed by a moral imperative known as punan, and hinting, rather than verbally demanding, for a share is considered the 'proper custom'. The 'external face' of the Menraq is usually one of shyness, timidity, subservience and fearfulness of strangers or gob. In the case of Rual, however, where people have maintained relatively longstanding interactions with outsiders and where people have come to expect to receive 'gifts' of development goods, some Menraq have cast away their shyness for a bolder personality.

\section{Gift Giving versus Gift Taking}

During my field research among the Menraq and the Semai, I have observed people giving food to one another on a regular basis. People do not share just wild foods that they obtain from hunting and gathering but also habitually distribute purchased food such as rice, dried fish, sugar, salt and biscuits as well as other consumables such as tobacco and cigarettes. The sharing ethic is strongly advocated in both communities. Young children are socialised to share their food and belongings with their neighbours; selfish people are often subjected to ridicule and malicious gossip.

In such distribution, the donor follows an order of priority according to social distance; as Endicott (1988: 116) observes for the traditional hunter-gatherer Batek people (a Menraq subgroup), 'they must give shares first to their own children and spouse, then to any parents-in-law or parents present, and finally to all other families in camp'. He declares that food sharing is 'an absolute obligation to the Batek, not something that the giver has much discretion over':

A person with excess food is expected to share it and if this is not done others do not hesitate to ask for some. And it would be virtually impossible for someone to hoard food in the open shelters of a Batek camp without everyone knowing about it. Recipients treat the food they are given as a right; no expression of thanks is expected or forthcoming, presumably because that would imply that the donor had the right to withhold it. (Endicott 1988: 117) 
Occasionally, this food-giving practice appears to be economically irrational, as people give each other the same sort of food. I have come across people giving rice they have bought in the market or a shop to their neighbours who would make a return in kind. There is no obvious benefit in levelling or redistribution in such food exchange. Endicott (1988: 116) says that ' $[\mathrm{t}]$ his apparently unnecessary distribution confirms that sharing of food is a dominant value in Batek culture'.

Why do foraging people accord such importance to sharing? As discussed in Peterson (1993), the standard anthropological explanation (cf. Sahlins 1972) is that sharing is a way of redistributing resources that are naturally spread widely and unequally among people in a group in order that everyone benefits and nobody is disadvantaged by the vagaries of the food quest. According to this view, people give food to others at times of plenty with an expectation of that being reciprocated at times of need. Governed by the principle of generalised reciprocity, a donor does not expect to receive a return gift from his or her recipient. Instead the donor's generosity is likely to be reciprocated by someone else in the group of people involved in reciprocal exchanges. In generalised reciprocity, sharing occurs within a group of people and the obligations to make a return gift are shared by the members of the group.

Woodburn (1980), amongst other anthropologists, associates sharing with egalitarianism - a salient feature of immediate-return foraging societies. As one would expect, the variation in productivity as a result of differences in skill, fortune, labour capacity and efficiency can impose some pressure on an egalitarian ethos. It is contended that increased productivity and the provision of greater quantities of food and other products can accord higher status or privilege to the producer. To minimise this or to remove this possibility, individuals are socially obliged through a set of rules, beliefs and norms that function to encourage, stimulate or subtly coerce people to share. Sharing is hence perceived to be a form of levelling mechanism, which serves to mitigate against accumulation and in the process operates to thwart or retard the development of inequalities of wealth, power and prestige.

When asked why they gave their food to their fellow camp members, Menraq offered reasons such as 'we must help each other', 'it's adat menraq [our custom]', 'we've always done this; it's a custom from our ancestors', and 'it's punan [taboo] not to do so'. These reasons - which are almost identical to the ones the Semai gave as to why they engage in sharing - touch on the sociality created by sharing in the consequentialist sense that it establishes and maintains social relations among members of the band or village. As Endicott (1988: 112) contends, '[t]he unity of a camp is based not on political organization...but on a moral obligation incumbent on each family to share food with all other families in the camp'. 
Talking to Menraq and Semai about sharing, my interlocutors never fail to stress that sharing is an act of gift giving and not gift taking. Anthony Williams-Hunt (personal communication, 7 October 2009) indicates that it is considered selseel (embarrassing) or dəəs (impolite) for Semai to make outright demands for food or other goods. ${ }^{3}$ People do, however, drop hints for a share, as Dentan (2008: 124) observes:

People who want some of your food or other goods will drop heavy hints (rather than make demands outright, which risks punan): 'I haven't eaten rice in days' or 'There's no side dish for my rice.' It is polite not to be explicit about your demand because demands are social pressure and, if the person does not have enough to make sharing reasonable, could produce punan.

Dentan (2008: 123) also notes, however, that '[s]ome lowland Perak Semai say that putting someone in punan by not eating together when invited or by not inviting a kawaad [friend] to eat when you have plenty is a "sin", tnghaan'.

\section{The Morality of Sharing}

The most significant moral imperative related to sharing is punan (among the Menraq) and phunan (among the Semai). These precepts, which appear to derive from the Malay kempunan, meaning yearning or desire, seem to be central in justifying as well as motivating sharing and gift giving in these two groups, as in most, if not all, other Orang Asli communities (for a discussion of morality and demand sharing in the Australian context, see Kwok, this volume). Endicott (1988: 117) describes punan, which he spells pohnen, among the Batek as 'a belief that to refuse a reasonable request for something can cause harm to the person refused'. My understanding of this concept differs somewhat from Endicott's. Rual people's explanation of punan appears to be similar to the Semai concept of phunan, which Robarchek (1977: 105) explains as the 'state of being unfulfilled, unsatisfied, or frustrated in regard to some specific and strongly felt want'. Someone who has incurred punan or phunan is believed to be at risk of attack by supernatural forces and/or wild animals and/or susceptible to accidental injury, illness and even death. Aptly, Van der Sluys (2000: 445) defines the concept (which she spells pehunen) as 'accident proneness'. Punan and phunan refer to the experience of unfulfilled desire as well as to the sanctions or punishment

\footnotetext{
3 Anthony Williams-Hunt (Bah Tony). I am grateful to Bah Tony for helping me understand better the various moral precepts in Semai sharing practices.

4 While Peterson (1993: 870) cautions that 'interviewing informants about their practices' could 'put them on their best behavior and leads them to present a normative account', these moral imperatives do structure social conduct in the 'known world' of the Semai and Menraq. This is not to deny that in reality some people might not do what they say they do.
} 
resulting from it. Since Menraq and Semai in a village are likely to be kin related and generally socially close to one another, a state of punan or phunan in one of its members is going to have implications for the whole group. As Van der Sluys (1999: 310) observes, '[a]ffliction falls on the victim, thus reinforcing the ethic of caring for one another'. In order to avoid punan or phunan, as Dentan (2008: 123) notes, a person might drop hints of his or her desire by making statements such as 'I haven't eaten rice for a while' or 'you have lots of tapioca in your rattan basket'. It is also important to note that one will run the risk of incurring phunan if one's request for a share is denied. This is yet another reason why Semai are reluctant to demand food and other items from someone else (Anthony Williams-Hunt, personal communication).

Semai are guided, along with phunan, by another precept, referred to as gnhaa?, which Anthony Williams-Hunt (personal communication) translates as 'abnormal behaviour'. This precept has wider applicability, but can be directly related to sharing. Failing to give to someone one has previously been a donor to or failing to reciprocate when one has previously received a share without any conceivable reasons for the failure is to have committed gnhaa?. Asking from someone whom one does not usually share with is also considered to be 'abnormal'. This indeed operates as a sanction against freeloaders - a sanction that Peterson (1993: 865) notes is required to ensure that generalised reciprocity is not 'undermined by freeloaders'. As with phunan, a person who has committed gnhaa? is believed to run the risk of becoming ill or experiencing accidental injury or some misfortune such as attack by a malevolent spirit or wild beast, or, worse still, death. Gnhaa? complements phunan in ensuring and maintaining sharing among the villagers.

\section{Changing Normative Orders and Sharing}

The moral precepts described above are embedded in traditional Menraq and Semai spiritual and cosmological orders. ${ }^{5}$ Breaking one of these taboos is believed to expose one to the possibility of supernatural punishment. In light of this, one might be tempted to argue that with religious conversion, as in the case of the Rual Menraq to Islam, the moral imperatives of sharing might lose their importance in the social lives of the people. It is also possible to argue that since there is no obvious ideological conflict between the moral precepts and Islamic principles and dogmas, the conversion of Menraq to Islam might be inconsequential as far as their sharing ethic is concerned. I do not have the sort of ethnographic evidence to come up with any clear conclusion here.

5 See Benjamin (1967), Dentan (2008), Endicott (1979) and Howell (1989) for detailed ethnographic treatises on the cosmological orders of several different Orang Asli groups. 
What is abundantly clear, however, is that economic transformation in terms of increased engagement in commodity production has had significant effects on sharing practices among the Menraq and the Semai.

Peterson (1993: 870) concedes that demand sharing could be 'a transitional phenomenon resulting from a breakdown in social obligations and surges in wealth differentials that the orthodox ethic of generosity cannot handle'. He goes on to state that 'demand sharing seems too deeply embedded in the daily practice of Aboriginal life and too integral to the tensions between autonomy and relatedness to be accounted for either by wealth differentials, disruption, poverty, or the entrenching of social inequality, although these things may have intensified the practice' (1993: 870, emphasis added). In the context of the Orang Asli, I would argue that it is precisely 'these things' that underscore the tendency for the Menraq to make outright demands for a share.

The question is: how is sharing affected by increased commoditisation? Has the extent of sharing declined and/or has the nature of sharing been transformed? In his study of the Agta Negritos of the Philippines, Griffin (1991: 219) observed sharing to be 'decreasingly important as nuclear families work hard to collect their own rattan, receive payment in cash and kind, and retain use of most of what is acquired'. With the lack of precise data on intra-community exchange transactions, it is difficult to say whether the custom of sharing has declined in Rual. Some of the people I interviewed assert that their fellow villagers do not share their food as much as formerly, but there is no definite consensus on this. There are, however, several changes in the village economy that could work against the widespread practice of sharing. The main Menraq activities of hunting, fishing and gathering produce perishable food, which, in the absence of storage facilities, needs to be consumed quickly. Furthermore, it is not possible to conceal food in the camp or hamlet given the openness of daily life in houses and hamlets. Hence, people share whatever surplus food they have with other families. The money earned from the sale of forest products is used mostly to buy food, which is shared in a similar way as domestically produced food. In the early days of resettlement, there was little cash available to producers or opportunities to buy consumer items such as clothes, household goods, cosmetics, and so on, and people did not earn enough to have money left over to hoard or save. Nowadays, with the greater range and quantities of consumer goods available to the Rual people from visiting traders and well-stocked shops in the nearby town of Jeli, people are presented with more than just foodstuffs to spend their money on. Furthermore, there are no obligations for Menraq to share cash, which, unlike food, can be hidden from others and hoarded.

Hunters are expected to share their game with other members of their band. The question is what happens if the wild meat can be sold for cash? Among the Semai, I found that, in contrast with the past when hunting primarily 
served subsistence purposes, people now hunt for commercial reasons. They sell game such as wild pigs, predominantly to outsiders. With commoditisation of hunting, a type of sharing of wild meat has emerged since the 1970s. I have referred to such sharing as commodified sharing, where the hunter would offer the game to his fellow villagers with an expectation of money in return. At the time of my research in the 1980s, hunters typically sold their game to people from villages other than their own, as it was then, as before, regarded improper to receive money from fellow villagers for wild meat (Gomes 2004: 161-2). The meat is distributed as in the traditional way, with two major differences: the cost of the meat is shared equally with each portion priced accordingly and recipients may request more than the one share that they are traditionally entitled to. The question here is whether asking or making a request for extra shares constitutes demand sharing as defined by Peterson (1993). One thing that is certain is that asking for more than what one is entitled to in commodified sharing is not considered by Semai as selseel (embarrassing) or dəəs (impolite).

As for Rual, I have not so far come across such a practice, but there seems to me no reason why it could not develop in the future. While the Menraq hunter might be tempted to take his game animal to the local market, social pressure is still strong enough that the animal is usually cooked or shared in the community. Hunting as such continues to be a collective benefit; however, the fact that people sell some game such as turtles and frogs rather than consume them domestically means they are no longer considered as food to be shared. Since such food can be readily converted into cash, it could end up being removed from the sphere of generalised reciprocity, indirectly reducing the number of things shared within the community. Endicott (personal communication) points out, however, that Batek still share food from the forest, such as saleable petai and honey, but it is the person who gathers it who decides how much to sell and how much to keep and share.

While it would be safe to assume, and in accordance with Rual people's claims, that sharing is in decline, there are instances of modifications and adaptations of traditional sharing practices to suit 'modern habits'. In 1976, on one of my trips to the shops in Jeli with Menraq from Rual, I witnessed an interesting sequence. On our way back to the resettlement, laden with provisions bought at the shops, a Menraq youth, Salim, accidentally dropped a large watermelon he had bought. The melon broke into several pieces. Our party stopped, some picked up the pieces of watermelon from the ground and began eating the fruit. A short while later, I observed each person giving some money to Salim. When I later asked two of the people who gave money to Salim why they had done so, I got several intriguing responses: 'we help one another', 'we have to share our losses', 'it's not fair to Salim if we don't give him money as we ate something he paid for'. The reasons given fit the Menraq sharing ethic squarely, but what 
is particularly interesting and revealing about this case is the encroachment of money into the traditional system of sharing. The fact that the watermelon was purchased and as such was a commodity removes it from the sphere of generalised reciprocity, where traditionally the food would be shared without an expectation of immediate return.

It would be reasonable to argue, then, that the normative obligations and rules that relate to gifts and reciprocity do not seem to have the same sort of meaning when the commodities are exchanged (or given) within the social group or village. The socially implicated dichotomy between gifts and commodities that Gregory $(1982,1997)$ delineates is particularly relevant here. As Gregory (1997: 52-3) contends, '[a] logical opposition between gifts (relations between non-aliens by means of inalienable things) and commodities (relations between aliens by means of alienable things) is the primary distinction'. I would argue that it is this dichotomy that Menraq and Semai apparently recognise that has a bearing on the moral imperatives related to sharing. There is an evident pattern that such moral imperatives tend to be strongest in the exchange of food and goods produced through subsistence-oriented activities and weakest in intracommunity sharing of commodities. This pattern will, however, need to be further investigated. In any case, Peterson's contention that some sharing occurs by benefactors making demands rather than solely through the pure altruism of the donor is applicable to some of the sharing events I observed among the Menraq and the Semai. I have not, however, come across any evidence to support the argument that such a form of sharing is 'deeply embedded' in or 'integral' to the social and cultural fabric among the people I studied, unlike what Peterson has suggested to be the case among Australian Aborigines. I would argue that the observed practice of demand sharing among the Menraq, which is normatively improper in the context of intra-community ('known world') relations among the Menraq and Semai, is an outcome of the changing normative orders following the process of commoditisation.

\section{References}

Benjamin, G. 1967. Temiar Religion. Unpublished PhD Thesis, Cambridge University, UK.

Benjamin, G. 1973 [1929]. Introduction. In P. Schebesta (ed.) Among the Forest Dwarfs, pp. v-xiv. London: Oxford University Press.

Dentan, R. 2008. Overwhelming Terror: Love, Fear, Peace, and Violence among Semai of Malaysia. Lanham, Md: Rowman \& Littlefield. 
Endicott, K. M. 1979. Batek Negrito Religion: The World-View and Rituals of a Hunting and Gathering People of Peninsular Malaysia. Oxford: Clarendon Press.

Endicott, K. M. 1988. Property, power and conflict among the Batek of Malaysia. In T. Ingold, D. Riches and J. Woodburn (eds), Hunters and Gatherers. Volume 2: Property, Power and Ideology, pp. 110-27. Oxford: Berg.

Gomes, A. G. 2004. Looking for Money: Capitalism and Modernity in an Orang Asli Village. Subang Jaya, Malaysia: Center for Orang Asli Concerns; and Melbourne: Trans Pacific Press.

Gomes, A. G. 2007. Modernity and Malaysia: Settling the Menraq Forest Nomads. London and New York: Routledge.

Gregory, C. 1982. Gifts and Commodities. London: Academic Press.

Gregory, C. 1997. Savage Money: The Anthropology and Politics of Commodity Exchange. The Netherlands and Australia: Harwood Academic.

Griffin, B. P. 1991. Philippine Agta forager-serfs: commodities and exploitation. In N. Peterson and T. Matsuyama (eds), Cash, Commoditisation, and Changing Foragers, pp. 199-222. Senri Ethnological Studies No. 30, National Museum of Ethnology, Osaka.

Howell, S. 1989. Society and Cosmos: Chewong of Peninsular Malaysia. Chicago: University of Chicago Press.

McKinley, R. 1976. Human and proud of it! A structural treatment of headhunting rites and the social definition of enemies. In G. N. Appell (ed.) Studies in Borneo Societies: Social Process and Anthropological Explanation, pp. 92-126. De Kalb, Ill.: Center for Southeast Asian Studies, Northern Illinois University.

Peterson, N. 1993. Demand sharing: reciprocity and the pressure for generosity among foragers. American Anthropologist 95 (4): 860-74.

Robarchek, C. 1977. Semai Non-Violence: A Systems Approach to Understanding. Unpublished PhD Dissertation, University of California at Riverside.

Sahlins, M. 1972. Stone Age Economics. Chicago: Aldine.

Sellato, B. 1994. Nomads of the Borneo Rainforest: The Economics, Politics, and Ideology of Settling Down. S. Morgan (trans.). Honolulu: University of Hawai'i Press. 
Van der Sluys, C. 1999. The Jahai of northern peninsular Malaysia. In R. Lee and R. Daly (eds), The Cambridge Encyclopedia of Hunters and Gatherers, pp. 307-11. Cambridge: Cambridge University Press.

Van der Sluys, C. 2000. Gifts from the immortal ancestors: cosmology and ideology of Jahai Semang. In P. Schweitzer, M. Biesele and R. Hitchcock (eds), Hunters and Gatherers in the Modern World: Conflict, Resistance, and Self-Determination, pp. 427-54. New York and Oxford: Berghahn Books.

Woodburn, J. 1980. Hunters and gatherers today and reconstruction of the past. In E. Gellner (ed.) Soviet and Western Anthropology, pp. 95-117. London: Duckworth. 